\title{
The lymphopenia (lyp ) gene controls the intrathymic cytokine ratio in congenic BioBreeding rats
}

\author{
S. Bieg ${ }^{1}$, C. Möller ${ }^{2}$, T. O Isson ${ }^{3}$, A . L ernmark ${ }^{1}$ \\ ${ }^{1}$ Department of Medicine, Robert H. Williams Laboratory, University of Washington, Seattle, USA \\ ${ }^{2}$ Department of Molecular Medicine, Karolinska Institute, Karolinska Hospital, Stockholm, Sweden \\ ${ }^{3}$ Department of Medicine, Karolinska Institute, Karolinska Hospital, Stockholm, Sweden
}

Summary The lymphopenia gene (lyp ) on rat chromosome 4 is closely linked to autoimmune diabetes in the BioBreeding (BB) rat. Lyp controls the number of peripheral lymphocytes by reducing $\mathrm{T}$ cells of the RT6 ${ }^{+}$phenotype by almost $90 \%$. Following nine cycles of marker-assisted cross-intercross breeding we have developed congenic lyp/lyp, lyp/ + and +1 + (wildtype) rats on the background of DR rats. Prediabetic and insulitis free lyp/lyp, Iyp/ + and $+/+$ rats were used to determine the effect of lyp on cytokine expression in the thymus. In situ hybridization of thymus cryosections showed that the interferon gamma (IFN $\gamma$ ) mRNA expression was highest in lyp/lyp rats and the hybridization signal was restricted to the medullary compartment. The frequency of IFN $\gamma$ and interleukin (IL)-10 mRNA expressing cells in isolated thymocytes determined by quantitative image analysis, demonstrated an increased IFN $\gamma:$ IL-10 ratio in thymocytes from lyp/lyp homozygotes compared to lyp/ + and $+/+$ rats. This confirmed a lyp gene dose-dependent segregation of the IFN $\gamma$ high phenotype. Recombinant human glutamic acid decarboxylase (GAD65) increased the number of IFN $\gamma$ and IL-10 mRNA expressing thymocytes after in vitro culture. We conclude that the quantitative ratio of cytokine producing thymocytes is associated with the lyp genotype. These potentially autoreactive thymocytes may explain the establishment of beta-cell directed autoimmunity in the BB rat despite peripheral lymphopenia. [Diabetologia (1997) 40: 786-792]

Keywords Diabetes mellitus, BioBreeding rat, lymphopenia, thymus, cytokines.
The destruction of the pancreatic beta cells in autoimmune type 1 (insulin-dependent) diabetes mellitus has been associated with autoimmune $\mathrm{T}$ cells producing interleukin-2 (IL-2) and interferon gamma IFN $\gamma$ [1-4]. Although the cell-mediated inflammatory process in the islets of Langerhans and

Received: 7 October 1996 and in revised form: 17 March 1997

Corresponding author: S. Bieg, Ph. D., Department of Medicine, Box 357710, Robert H. Williams Laboratory, University of Washington, Seattle, WA 98195-7710, USA

A bbreviations: ANOVA, Analysis of variance; BB, BioBreeding; DP, diabetes prone; DR diabetes resistant; HLA, human histocompatibility antigen; IFN, interferon; IL, interleukin; mRNA EC, mRNA expressing cells; MHC, major histocompatibility complex; PCR, polymerase chain reaction; RAG, recombination activating gene; rhGAD, recombinant human glutamic acid decarboxylase; TCR, T-cell receptor. the development of diabetes in the animal models can be prevented by early treatment with beta-cell antigens $[5,6]$, the generation of autoreactive $T$ cells is not understood. A failure in the development of central tolerance $[7,8]$ or peripheral ignorance [9] may give rise to autoreactive $\mathrm{T}$ cells, and thus distort the equilibrium of functionally different T-cell subsets $[5-8,10]$.

It is not known how peripheral antigens encounter and genetic predisposition contributes to the development of tissue directed autoreactivity. Diabetes in man [11] and in the non-obese-diabetic mouse [12] has been linked to several susceptibility loci some of which reside near candidate genes capable of mediating diabetes immunopathogenesis, such as genes within the HLA [11, 13] or the IL-1 cluster [14, 15]. However, the allelic variation of the respective genes and incomplete penetrance make it difficult to dissect 
the role of individual genomic loci associated with diabetes. The lymphopenia gene (lyp ) on rat chromosome 4 (Iddm-1) and the RT1B ${ }^{\mathrm{u}}$ MHC class II allele on rat chromosome 20 (Iddm-2) genetically control diabetes in the inbred BioBreeding (BB) rat [16]. Lyp causes the almost complete absence of peripheral RT6 $^{+}$T cells $^{2}[17,18]$. It is suspected that RT6 ${ }^{+}$ $\mathrm{T}$ cells suppress autoreactivity, since diabetes development was abrogated after adoptive transfer of $\mathrm{RT6}^{+}$T cells [19]. Reduced responsiveness to alloantigenic stimulation $[20,21]$ and the analysis of cell surface differentiation markers $[22,23]$ have implied that $\mathrm{BB}$ rat $\mathrm{T}$ cells have a phenotype characteristic of immature early thymic migrants suggesting an abnormal cell subset distribution in the BB rat thymus. Decreased numbers of mature T-cell receptors $(\mathrm{TCR})^{\text {high }} \mathrm{CD}^{+}{ }^{+} \mathrm{CD} 8{ }^{+}$and $\mathrm{TCR}^{\text {high }} \mathrm{CD} 4{ }^{-} \mathrm{CD} 8^{+}$have been reported [24], and it has further been suggested that lyp interferes in T-cell maturation steps occurring after the recombination associated gene (RAG)-1 and RAG-2 mediated rearrangement of the TCR [25]. However, none of these thymic phenotypes has been linked to lyp, and it is unclear how lyp allows islet specific, autoreactive $\mathrm{T}$ cells to be generated despite profound peripheral lymphopenia.

We have localized lyp in a cross-intercross between specific pathogen free, inbred diabetes prone (DP) and MHC-identical, diabetes resistant (DR) $\mathrm{BB}$ rat lines [16, 26]. Marker-asssisted cyclic cross-intercross breeding in 9 cycles has allowed introgression of lyp into the DR line so that the three resulting genotypes have the same DR genomic background except on the lyp locus on rat chromosome 4 [16, 27]. Lyp/lyp have lymphopenia at birth and are diabetes prone (DP), lyp/ + have normal lymphocyte numbers and are diabetes resistant (DR) and wildtype $+/+$ rats have normal lymphocyte numbers and are also diabetes resistant (DR).

In this study we have used prediabetic, but insulitis free lyp/lyp and age matched lyp / + and $+/+$ rats to test the hypothesis that lyp is linked to the presence of IFN $\gamma$ and IL-10 producing T cells in primary lymphoid tissue. We used in situ hybridization and the immunospot assay [28-30] to quantify lymphocytes that are either potentially autoagressive and produce IFN $\gamma$, or produce IL-10 and are potentially non-agressive. By using a novel approach to combine quantitative and qualitative analysis of single cytokine mRNA expressing cells, we present data that lyp/lyp rats show an increased IFN $\gamma$ :IL-10 ratio due to an increased frequency of IFN $\gamma$ producing cells in the thymus. This ratio represents a phenotype that segregated with lyp.

\section{Materials and methods}

A nimals. The BB rats used in this study were developed by cyclic cross-intercross breeding using inbred diabetes prone (DP) and diabetes resistant (DR) BB rats. Introgression of lyp onto the DR genetic background was initiated in 1989 by $(\mathrm{DP} \times \mathrm{DR}) \mathrm{F} 1$ cross-intercross breeding, selecting a diabetic and lymphopenic $\mathrm{F} 2$ rat to be crossed with a DR rat to initiate each cycle. All rats in the F2 generations are lyp-genotyped for both R236 (D4Mit6) and npy (D4Mit7) which are flanking markers of lyp $[16,31]$. The lyp phenotype is determined by flow cytometric analysis of $\mathrm{CD}^{+}$peripheral blood lymphocytes. The frequency of peripheral $\mathrm{CD}^{+}$cells in our lyp/lyp rats is below $15 \%$. Diabetes in lyp/lyp rats develops gender independently at 50 to 90 days of age with an incidence of $100 \%$. Lyp/ + and + / + rats develop neither lymphopenia nor diabetes. The DP and DR rats are kept and bred under specific pathogen free conditions. For this study, all rats were used at the age of 60 days unless otherwise indicated. All animals were insulitis free as determined by histological analysis of pancreatic cryosections.

Preparation of crysections. 60-day-old lyp/lyp, Iyp/ + and + / + rats were killed with $\mathrm{CO}_{2}$ and the thymus was removed immediately. After rinsing in sterile phosphate buffered saline (PBS) to remove residual blood, the tissue was embedded in Tissue-Tek OCT compound (Miles Inc., Elkhart, Ind., USA) and shock frozen in isopentane/liquid $\mathrm{N}_{2}$. We prepared $14 \mu \mathrm{m}$ sections using a cryostat and were mounted on Fisher Plus slides (Fisher, Springfield, Ill., USA). Each slide contained tissue sections from each of the three genotypes and was stored at $-80^{\circ} \mathrm{C}$.

I solation of rat thymocytes and preparation of cytospot slides. In each experiment lyp/lyp were analysed in parallel with lyp/ + and $+/+$ rats to minimize interassay variations. Each type of experiment was repeated at least three times, with a total of 5-7 rats of each genotype unless otherwise indicated. The animals were killed with $\mathrm{CO}_{2}$ and the thymus was removed quickly. Thymocytes were obtained by forcing the tissue through sterile metal strainers. The preparations were visibly free from erythrocytes. The cell suspensions were washed several times in sterile cell culture medium (Dulbecco's modified medium (Life Technologies, New York, N. Y., USA), supplemented with $10 \%$ heat inactivated fetal calf serum (Life Technologies), $50 \mathrm{IU} / \mathrm{ml}$ penicillin, $60 \mu \mathrm{g} / \mathrm{ml}$ streptomycin (Life Technologies), $1 \%(\mathrm{v} / \mathrm{v})$ minimum essential medium (Life Technologies) and $2 \mathrm{mmol} / \mathrm{l}$ glutamine (Life Technologies)). This medium was used in all cell cultures described in this study. Cells were plated at $10^{6}$ cells/well in round bottomed microtitre plates or, for the IFN $\gamma$-immunospot analysis, in nitrocellulose bottomed plates (Millipore, Bedford, Mass., USA). The thymocytes were cultured for $24-72 \mathrm{~h}$ at $37^{\circ} \mathrm{C}$ and $5 \%(\mathrm{v} /$ v) $\mathrm{CO}_{2}$ in the presence or absence of GAD65 or recombinant human proinsulin (provided by Eli Lilly, Indianapolis, Ind., USA) as a control. Recombinant human proinsulin served as a control antigen since it did not induce any significant cytokine production as determined in preliminary studies (data not shown). Cells were then washed in sterile saline, applied as cytospots (approximately $1.5 \times 10^{4}$ cells/spots) to sterile Fisher Plus slides and dried at $55^{\circ} \mathrm{C}$. Cytospots with cells from the negative (medium alone) and the positive control (Con A) were included on each slide to obtain comparable standards for silver grain formation during emulsion autoradiography. Slides were kept at $-80^{\circ} \mathrm{C}$ until further use.

I mmunospot assay. Nitrocellulose bottomed 96-well microtitre plates were coated overnight with anti-rat IFN $\gamma$-monoclonal 
antibody (DB1) as described [32]. $10^{6}$ cells per well were plated in $200 \mu \mathrm{l}$ of cell culture medium. Antigens at $0.01,0.1$ and $1 \mu \mathrm{g} /$ $\mathrm{ml}$ or $5 \mu \mathrm{g} / \mathrm{ml}$ Con A (Sigma, St Louis, Mo., USA) were added. As a negative control, cells were kept in culture medium alone. Each parameter was tested in quadruplicate. The cells were incubated for $48 \mathrm{~h}$ at $37^{\circ} \mathrm{C}$ and $5 \%(\mathrm{v} / \mathrm{v}) \mathrm{CO}_{2}$. The cells were removed and the plates were washed several times in saline. Rabbit anti-rat IFN $\gamma$-antibody (diluted 1/1000) was added at $100 \mu \mathrm{l} /$ well. After incubation overnight at $4{ }^{\circ} \mathrm{C}$, the plates were washed repeatedly and biotinylated goat anti-rabbit-IgG (Vector, Burlingame, Calif., USA) was applied for $2 \mathrm{~h}$ at room temperature, followed by incubation with avidin-streptavidin-peroxidase complex (Vector). After colour development using 3amino-9-ethylcarbazole (Sigma), bound IFN $\gamma$ was visible as brown-reddish spots on the nitrocellulose which were counted in a dissection microscope. No spots could be detected in specificity control experiments in which the rabbit anti-rat IFN $\gamma$ antibody had been omitted or in which DB-1 has been replaced by an irrelevant mouse monoclonal antibody. The variation between the quadruplicates was less than $15 \%$.

In situ hybridization. A cocktail of 4 template specific 48-mer cDNA oligonucleotide probes was used for each cytokine. The cDNA sequences were obtained from GenBank by use of the MacVector system. The cytokines of interest and their complementary probes were rat IFN $\gamma$ (bases 298-345, 80-125, 303350, 180-227; GenBank numbers \# M29315, M29316, M29317, respectively) and mouse IL-10 (bases 79-126, 134-181, 184231, 402-449, GenBank accession number \# M37897). As a control for non-specific binding of the oligonucleotide probes, a sense probe for IFN $\gamma$ was used. The probes were 3 '-end labelled with ${ }^{35} \mathrm{~S}$-labelled-deoxyadenosin 5 '-thiotriphosphate $\left({ }^{35} \mathrm{~S}\right.$-dATP). Hybridization of the target was carried out as reported [30]. Briefly, hybridizing temperature was $42^{\circ} \mathrm{C}$ with $10^{7} \mathrm{cpm}{ }^{35} \mathrm{~S}$-labelled probes $/ \mathrm{ml}$ hybridization cocktail. The slides were washed in $1 \times$ standard sodium citrate $($ SSC) at $55^{\circ} \mathrm{C}$, dried and treated with photoemulsion (Kodak, Rochester, N. Y., USA). After a 2-week exposure the slides were developed and counterstained with $0.4 \%$ cresyl violet. The numbers of positive cells per cytospot were counted manually in a blinded way on coded slides harbouring the cytospots using a Nikon Optiphot microscope (Melville, N. Y., USA) and each positive cell was further examined by image analysis (see below) in order to determine the cytokine mRNA expression level.

Image analysis. Images were retrieved with a Nikon Optiphot microscope connected to a charge-coupled device (CCD) camera. For digitalization and data processing image analysis software and hardware (Molecular Computer Imaging Device; MCID, Imaging Research Inc., Ontario, Canada) was used. Screen resolution for display of the digitalized images was $1280 \times 1024$ pixel in 8 bit monochrome/256 grey levels. Positive cells were analysed in the dark field. Grain size ( $>15$ pixel), scan area $(30 \mu \mathrm{m})$ and relative optic density values were determined as background discrimination criteria for automated counting before each session. These conditions were set as default parameters and were therefore kept equal throughout the entire session. Generally, background grain numbers were less than 30 grains per scan area. The grains from all positive cells per cytospot were considered to reflect the level of mRNA expression of the thymocytes in the respective cytospot and were added up in a cumulative histogram. For quantitative analysis of the relative levels of mRNA the histogram areas were calculated in metric units $\left[\mathrm{mm}^{2}\right]$. The morphological signal distribution on the thymus cryosections was determined by examination of the sections in the bright field. Then, the spatial extension of the signal distribution area was deter- mined and the signal strength was expressed as the proportion of grains/area using the dark field together with similar background exclusion parameters as described for examination of the cytospots.

Statistical analysis. Statistical analysis of the results was performed using the Wilcoxon two sample test for non-parametric analysis. $P$-values equal to or smaller than 0.05 were considered to be significant. Gene-dose effects on the three genotypes were analysed by one-way analysis of variance (ANOVA).

\section{Results}

First, the expression of IFN $\gamma$ and IL-10 mRNA in freshly isolated thymus was determined in order to examine the effect of lyp on thymocytes within the intact histological structure. We used cryosections of freshly isolated thymus tissue from 60-day-old lyp/ lyp and age matched lyp/ + and wildtype $+/+$ rats (Fig.1). We found that the hybridization signal for either cytokine mRNA was restricted to the medullary compartment. The hybridization signals in the medullary compartments were quantified by image analysis and expressed as the proportion of the total grain area $\left[\mu \mathrm{m}^{2}\right]$ per $\mu \mathrm{m}^{2}$ medulla (Fig. 2). We found an increased proportion of IFN $\gamma$ mRNA expression in the medulla of lyp/lyp rats $(0.098 \pm 0.041)$ compared to $\mathrm{lyp} /+(0.018 \pm 0.004)$ and $+/+$ rats $(0.009 \pm$ $0.005)$. The IFN $\gamma$ mRNA expression - highest in lyp/ lyp and lowest in + / + rats - was lyp dose dependent as determined by ANOVA $(p<0.001)$. On the other hand, Iyp /lyp rats had decreased IL-10 mRNA expression compared to the wildtype $(0.021 \pm 0.006$ and $0.032 \pm 0.009$ for lyp/lyp and $+/+$, respectively $)(p<0.04)$. This inverse relationship between IFN $\gamma$ and IL-10 mRNA expression might reflect antagonistic paracrine interactions [32-34].

Next, we determined the ratio between IFN $\gamma$ and IL-10 mRNA expressing cells in cultured thymocyte populations from lyp/lyp $(n=5)$, lyp/ $+(n=7)$ and $+/+(\mathrm{n}=5)$ rats. We asked whether the exposure of thymocyte cultures to GAD65 would alter the cytokine expression. Dark field images of cultured thymocytes were analysed after in situ hybridization in order to analyse the number of cytokine mRNA expressing cells (EC) within a given thymocyte population per cytospot (illustrated in Fig. 3a-e). For each examined rat, the maximum number of cytokine mRNA EC per cytospot was determined after 24$48 \mathrm{~h}$ in vitro culture (Fig. $4 \mathrm{a})$. We found increased numbers of IFN $\gamma$ mRNA EC $(8.9 \pm 2.2 /$ cytospot $)$ in the unstimulated thymocyte cultures of lyp/lyp rats when compared to $3.0 \pm 1.4$ in lyp/ $+(p<0.001)$ and $1 \pm 1.2$ in $+/+$ rats $(p<0.001)$. In contrast, the number of IL-10 mRNA EC in these populations was comparable in all three genotypes (12.4 \pm 8.3 , $11.3 \pm 5.9$ and $10.8 \pm 9.6$ for lyp/lyp, lyp/ + and $+/+$, respectively). The ratio of IFN $\gamma$ : IL-10 mRNA EC in 


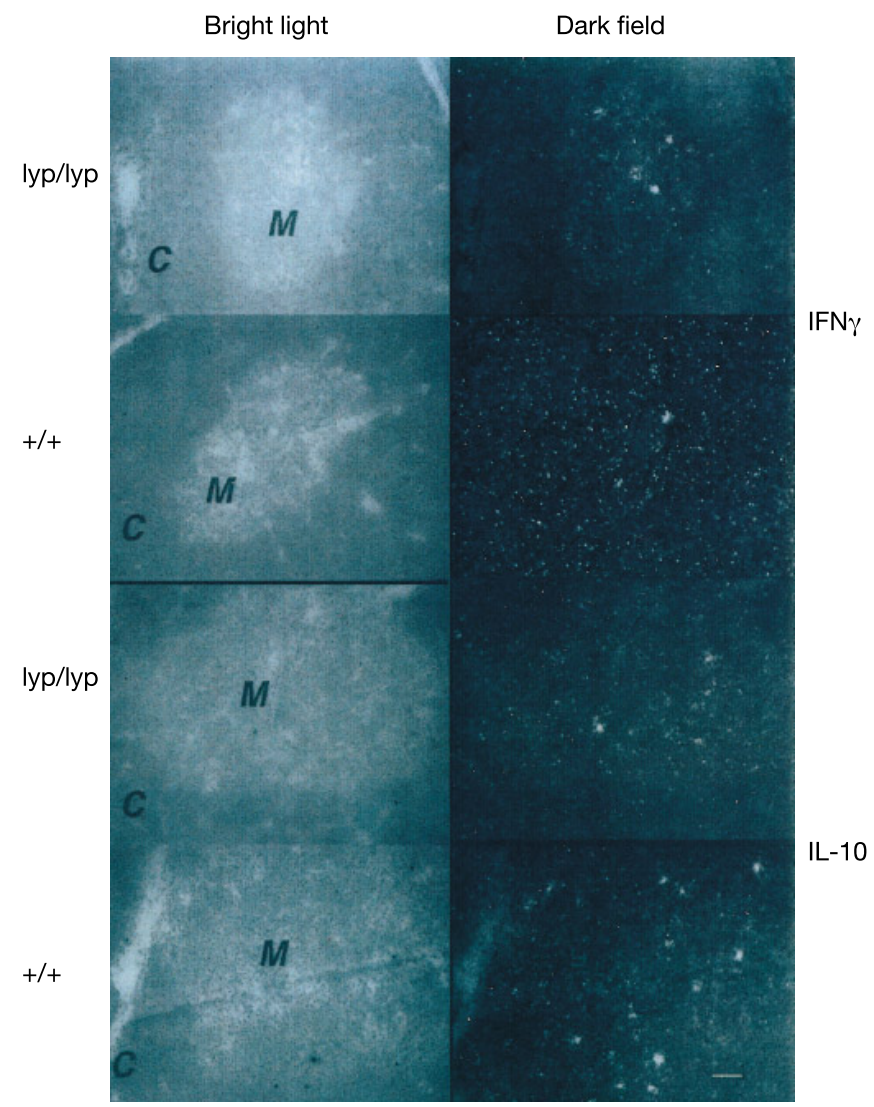

Fig. 1. IFN $\gamma$ and IL-10 mRNA expression in the thymus medulla from lyp/lyp and $+/+B B$ rats. Thymus cryosections $(14 \mu \mathrm{m} \varnothing)$ from 60-day-old lymphopenic lyp/lyp and non-lymphopenic $+/+\mathrm{BB}$ rats were hybridized with ${ }^{35} \mathrm{~S}$-labelled cDNA probes in order to detect IFN $\gamma$ and IL-10 mRNA expression. After autoradiography, the hybridization signals were localized histologically in bright light (dark grains) and then quantified in dark field (light grains) by image analysis. Shown are images from identical thymus cryosections in bright light and dark field. For quantification results see Figure 2. Scale bar, $50 \mu \mathrm{m}$. Magnification $\times 225$

the thymocyte populations was increased in lyp/lyp compared to $\mathrm{yp} /+(\mathrm{p}<0.01)$ and $+/+$ rats $(p<0.002)$. In vitro stimulation with $0.01 \mu \mathrm{g} / \mathrm{ml}$ GAD65 (dose eliciting maximum cytokine response, data not shown) resulted in the expansion of IFN $\gamma$ as well as Il-10 mRNA expressing thymocytes in all three genotypes and therefore did not alter the IFN$\gamma:$ IL-10 ratio already present in the respective unstimulated thymocyte populations.

In order to quantify the relative amount of mRNA per positive cell, we computed the number of grains per positive cell per cytospot by quantitative image analysis. Figure $4 \mathrm{~b}$ shows that the IFN $\gamma$ mRNA expression in non-stimulated thymocytes from lyp/lyp rats was increased approximately sevenfold compared to thymocytes from $+/+$ rats as indicated by the total histogram area $(88.6 \pm 33.1$ and $12.4 \pm$ $3.8 \mathrm{~mm}^{2}$, respectively, $\left.(p<0.01)\right)$. In the immunospot assay, we found an increased number of IFN $\gamma$ secret-

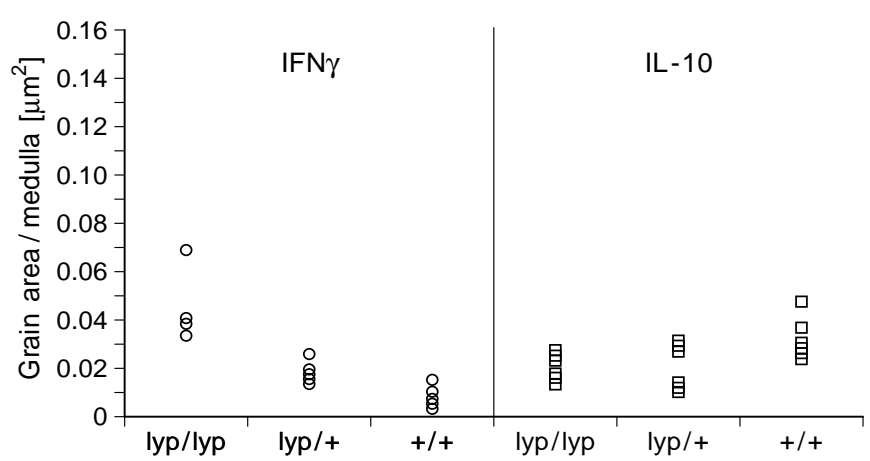

Fig. 2. Quantification of the IFN $\gamma$ and IL-10 mRNA expression in the thymus medulla of lyp/lyp, lyp/ + and $+/+$ BB rats. After in situ hybridization, the number and spatial distribution of the silver grains indicating IFN $\gamma$ and IL-10 mRNA expression on thymus cryosections (compare Figure 1). from lyp/lyp, lyp $/+$ and $+/+$ rats $(n=5$ each $)$ were computed using the Molecular Computer Imaging Device (MCID) system. The proportion of grain area $\left[\mu \mathrm{m}^{2]}\right.$ per $\mu \mathrm{m}^{2}$ medulla area was determined for each cytokine. Plotted are the mean values for each rat obtained by analysing 4-7 medullary areas/cytokine/individual rat, depending on the section size. Approximately $2 \times 10^{5} \mu \mathrm{m}^{2}$ medulla was examined per animal. Differences in mRNA expression between the genotypes were analysed by one-way analysis of variance (ANOVA)

ing thymocytes in 60-day-old lyp/lyp rats $(12.8 \pm 3.9$ IFN $\gamma$ secreting cells $/ 10^{6}$ ) compared to an age matched lyp / + control group that had $4 \pm 2.4$ IFN $\gamma$ secreting thymocytes $/ 10^{6}(p<0.008$, data not shown) indicating a difference in IFN $\gamma$ production not only on mRNA but also on protein expression level. Thymocytes from $+/+$ rats showed the highest level of IL-10 mRNA expression per cytospot represented by a histogram area of $385.8 \pm 167.9 \mathrm{~mm}^{2}$ compared to $168.4 \pm 56.8 \mathrm{~mm}^{2}$ for lyp/ + and $100.2 \pm 24.1 \mathrm{~mm}^{2}$ for lyp/lyp thymocytes as determined by ANOVA $(p<0.001)$. The IFN $\gamma$ :IL-10 ratio shown in Figure $4 b$ showed a significant difference between the three genotypes $(p<0.0001)$. We conclude that there is a lyp gene dose effect on the IFN $\gamma:$ IL-10 ratio in thymocytes from lyp/lyp, lyp/ + and + / + rats.

\section{Discussion}

In the $\mathrm{BB}$ rats generated for this study, the diabetes phenotype segregates as a single recessive trait controlled by lyp. We show that there is also a linkage between lyp and a distinct IFN $\gamma^{\text {high }}$ phenotype and therefore increased IFN $\gamma$ :IL-10 ratio in the thymus of BB rats both of which also segregate as lyp dependent traits. Due to the paracrine and autocrine function of cytokines regarding $\mathrm{T}$-cell activation and expansion, our results could explain how autoreactive $\mathrm{T}$ cells are generated in the otherwise severely lymphopenic BB rat. At 60 days of age none of the rats had any detectable intra-islet infiltration which indicates that the increased intra-thymic IFN $\gamma:$ IL-10 


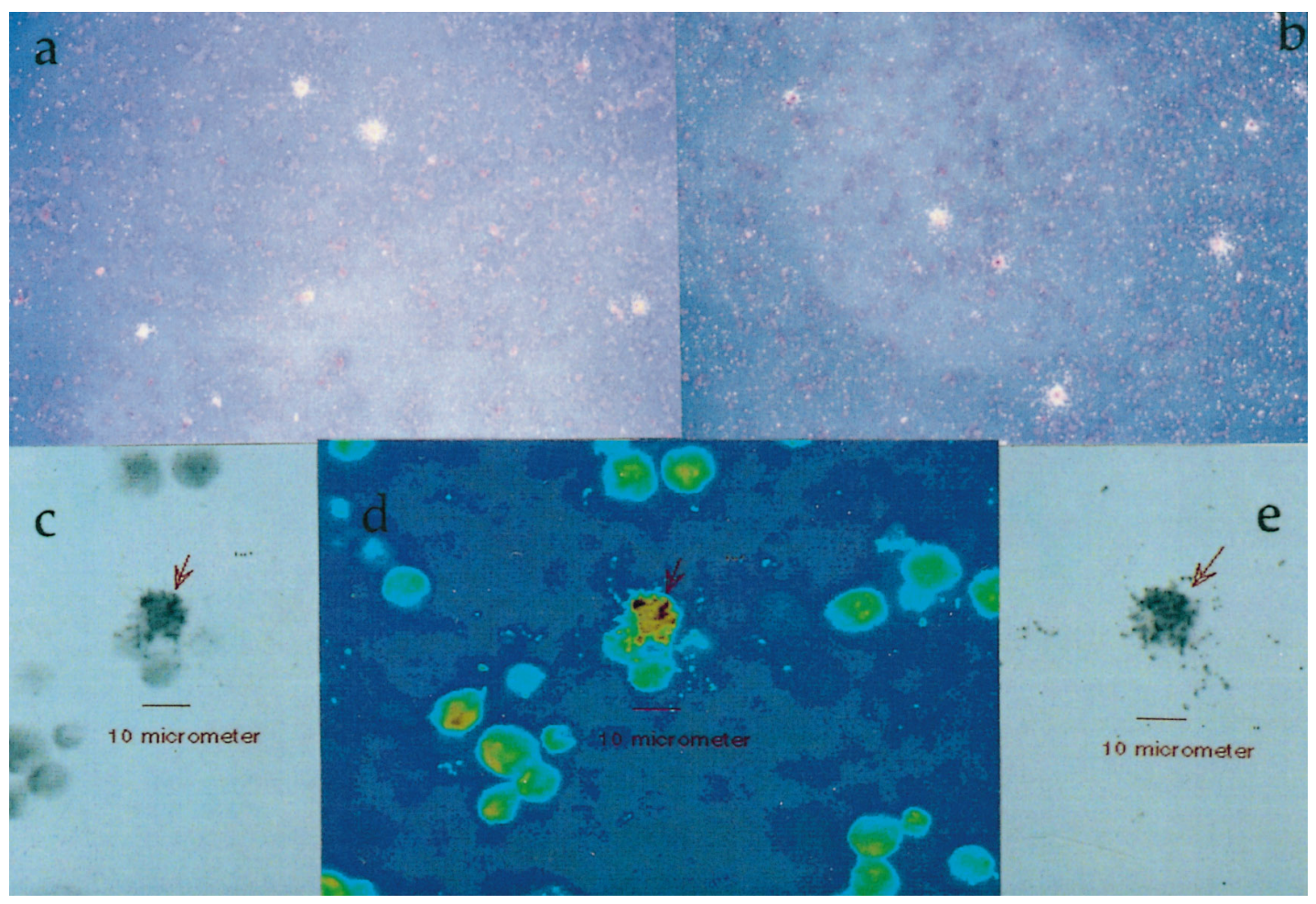

Fig. 3a-e. Background exclusion by polarized darkfield microscopy of thymocyte cytospots after in situ hybridization. In situ hybridization of IFN $\gamma$ (a, c-d) and IL-10 (b) mRNA expressing thymocytes obtained from 60-day-old, prediabetic lyp/lyp rats. Results are shown as dark field photographic images (magnification $\times 100$ ) in (a) and (b). Positive cells are marked by silver grains overlaying the cell body. The digitalized image of one single IFN $\gamma$ mRNA expressing cell (arrow) is shown in bright light (c), false colour enhancement (d) and after background exclusion by dark field polarisation (e) with the MICD system (magnification $\times 450$ ). Scale bar, $10 \mu \mathrm{m}$. The thymocytes were cultured for $48 \mathrm{~h}$ and then applied to microscopic slides as cytospots with $1.5 \times 10^{4}$ cells per cytospot. In situ hybridization was performed with ${ }^{35} \mathrm{~S}$-labelled rat IFN $\gamma$ and IL-10 cDNA oligonucleotide probes. Image analysis on each positive cell per spot was performed by defining a default scan area around the positive signal $(30 \mu \mathrm{m}$ diameter $)$ and by background exclusion ( $\mathrm{ROD}>0.45$, grain size $>15$ pixel)

cytokine ratio in these rats was independent from the local inflammatory process in the islets causing immune activation prior to diabetes onset [36, 37].

The examination of individual cytokine expressing lymphocytes by image analysis permitted the quantification of the relative magnitude of the expression signal per single cell. Each cytokine mRNA expressing cell was entered in the algorithm both numerically and qualitatively in order to distinguish the IFN$\gamma:$ IL-10 profiles that we found in the three genotypes. Conventional Northern blot hybridization requires considerable amounts of tissues or cells which could not be obtained after in vitro culture of the thymocytes without further amplification e.g. by reverse transcription PCR [37].
The role of GAD65 as an autoantigen in BB rat diabetes is unclear. We found that lyp/lyp as well as lyp/ + and + / + rats contained GAD65 reactive thymocytes. Autoreactive lymphocytes in DR rats have been reported before [38] and insulitis and diabetes are inducible in DR rats $[39,40]$ suggesting a regulatory system in DR rats that controls this latent autoreactivity. IFN $\gamma$ and IL-10 producing thymocytes might be activated by different antigenic epitopes on the GAD65 molecule as a means of controlling the development of thymocyte subsets, but there is no evidence so far for intrathymic differential display of self-peptides. On the other hand, deficiency in $\mathrm{MHC}$ class $\mathrm{II}^{+}$expression on $\mathrm{BB}$ rat thymic epithelial cells [41] may result in altered or absent antigen presentation and may therefore allow autoreactive $\mathrm{T}$ cells to escape into the periphery. However, GAD65 does not seem to be expressed in noticeable amounts in the BB rat thymus (C.Møller, unpublished data). We and others [42] could not prevent diabetes by injection of rhGAD65 into young lyp/ lyp rats, although we did decrease the frequency of IFN $\gamma$ producing thymocytes in the injected rats (data not shown) which needs to be further investigated in order to overlook the role of GAD65 in $\mathrm{BB}$ rat diabetes.

Intra-islet expression of IL-10 in the mouse accelerates insulitis and diabetes onset [43], an observation that opposes the idea that Th2 cells and their cytokines might have beneficial effects for diabetes development [10]. Our results show that the IL-10 mRNA expression was decreased in lyp/lyp thymocytes compared to thymocytes from lyp/ + and 


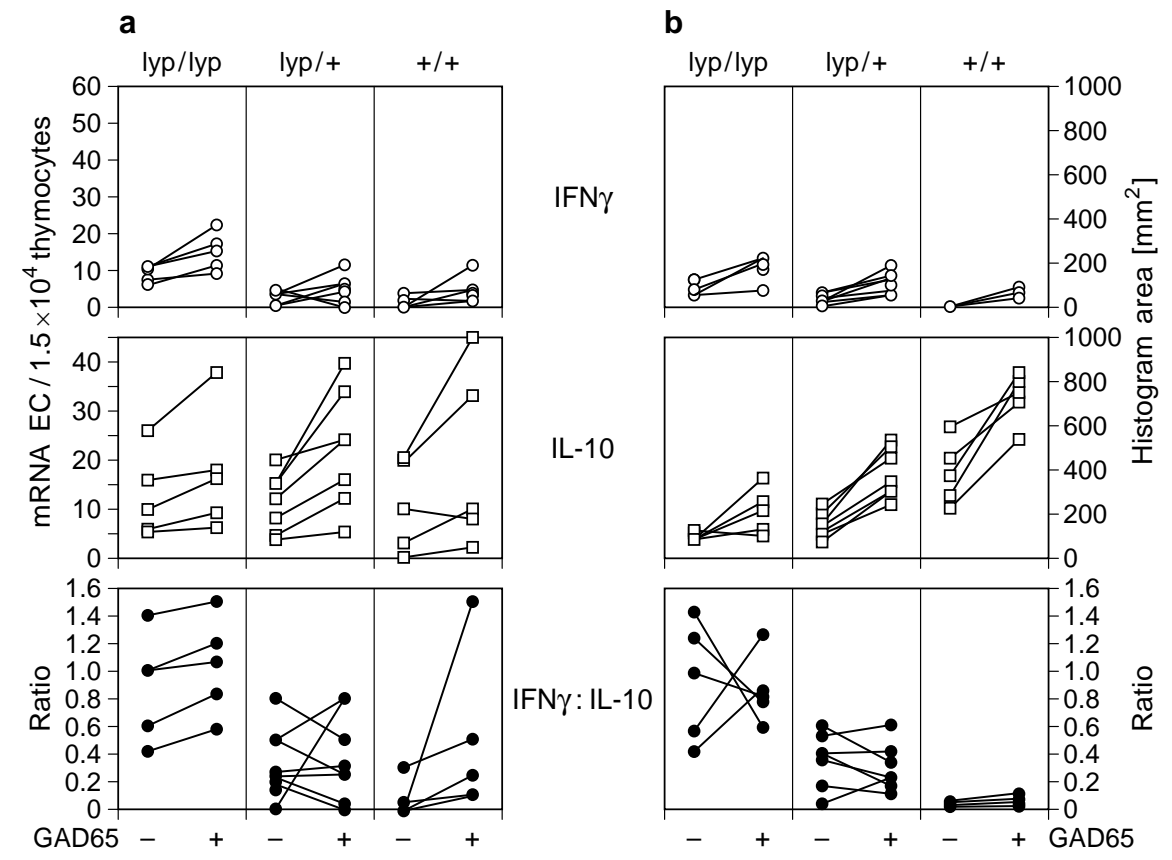

b

Fig. 4a, b. IFN $\gamma$ and IL-10 mRNA expression on cultured thymocytes from lyp/lyp, lyp/ + and $+/+$ BB rats. Whole thymus cell populations obtained from 60-day-old lyp/lyp $(n=5)$, lyp/ $+(n=7)$ and $+/+(n=5)$ rats were cultured for 24 to $48 \mathrm{~h}$ in absence or presence of $0.01 \mu \mathrm{g} / \mathrm{ml}$ GAD65 and then distributed on microscopic slides as cytospots (approximately $1.5 \times 10^{4}$ cells). In situ hybridization was performed with ${ }^{35} \mathrm{~S}$-labelled rat IFN $\gamma$ and mouse IL-10 oligonucleotide probes for each culture population. IFN $\gamma$ and IL-10 mRNA expressing cells (EC) and their ratio before (-) and after (+) GAD65 stimulation were determined both numerically (a) and by quantitative image analysis (b) for each rat. Maximum values after $24-48 \mathrm{~h}$ in vitro culture are plotted. For (b), the numerical information on the number of cytokine EC population calculated in (a) was extended by quantifying for each indiviual positive cell the grains reflecting its IFN $\gamma$ or IL-10 mRNA expression. This information was accumulated in individual cumulative histograms for each cytokine and rat and the spatial dimension of the histograms was calculated in $\mathrm{mm}^{2}$. Cell cultures before and after in vitro stimulation are represented by a pair of connected symbols. Differences in the IFN $\gamma$ :IL-ratio in (b) were determined by one-way analysis of variance (ANOVA)

$+/+\mathrm{DR}$ rats. However, this was rather due to decreased expression levels than to a reduced frequency of IL-10 mRNA EC. In the mouse, IL-10 inhibits monocyte-induced IFN $\gamma$ production by Thelper cells, but it does not inhibit activation of Th1 cells by dendritic cells [33]. Interdigitating dendritic cells represent a major fraction of the stromal cell mixture in the thymus and might be involved in T-cell selection mechanisms [44]. Therefore, IL-10 mRNA expression in the medullary compartment of the $\mathrm{BB}$ rats might participate indirectly in thymocyte subset development by paracrine activation of antigen presenting interdigitating cells in the cortex and the cortical medullary junction area. In combination with an overrepresentation of cytokines such as IFN $\gamma$ or after the presentation of a self-peptide, this might either lead to the formation of autoreactive $\mathrm{T}$ cells or to the establishment of regulatory processes.

In conclusion, our data show that the frequency of IFN $\gamma$ and IL-10 mRNA expressing thymocytes represent a lyp dose dependent phenotype in the BB rat. Although we do not know the mechanism by which lyp affects intrathymic cytokine expressing cells, the influence of lyp on paracrine signals may result in clonal expansion or deletion of certain T-cell subsets during intrathymic maturation. The thymus may serve as a source of autoreactive $\mathrm{T}$ cells due to the lyp allele frequency dependent IFN $\gamma^{\text {high }}$ profile which was present from pre-insulitis (day 60) to past disease manifestation. Together with an absence of regulatory cells this might resolve in an inflammatory reaction in the pancreas and the development of diabetes. We are currently investigating the presence and influence of other cytokines in our cultures and on tissue sections of thymus, spleen and pancreas in order to dissect the T-cell pool which is associated with insulitis and diabetes. The characterization of the IFN $\gamma$ producing $T$ cells in the thymus of Iyp/lyp rats may explain the pathogenesis of $\mathrm{BB}$ rat diabetes.

A cknowledgements. We wish to thank Dr. Abdel-Moiz Omer Bakhiet, Dr. Maha Mustafa and Dr. Shohreh Issazadeh, Karolinska Institute, Stockholm, Sweden, for discussing the in situ hybridisation and the immunospot assay, Dr. John Breininger and Dr. Denis Baskin, Veterans Affairs Hospital, Seattle, USA for discussing the image analysis system, Kristina Edwardsson for excellent handling of the BB rat colony and Sue Blaylock for secretarial help. This work was supported by grant DK 46620 from the National Institutes of Health. S. B. is supported by a Postdoctoral Fellowship from the Deutsche Forschungsgemeinschaft, Bonn, Germany. 


\section{References}

1. Jiang Z, Woda BA (1991) Cytokine gene expression in the islets of the diabetic Biobreeding/Worcester rat. J Immunol 146: 2990-2994

2. Bach J-F (1994) Insulin-dependent diabetes mellitus as an autoimmune disease. Endocrine Rev 15: 516-542

3. Edouard P, Hiserodt JC, Plamondon C et al. (1993) CD8+ Tcells are required for adoptive transfer of the $\mathrm{BB}$ rat diabetic syndrome. Diabetes 42: 390-397

4. M'Etroz D-MD, Mouland A, Brideau C et al. (1990) Adoptive transfer of diabetes in $\mathrm{BB}$ rats induced by $\mathrm{CD} 4 \mathrm{~T}$ lymphocytes. Diabetes 39: 928-932

5. Posselt AM, Barker CF, Friedman AL et al. (1992) Prevention of autoimmune diabetes in the BB rat by intrathymic islet transplantation at birth. Science 256: 1321-1324

6. Leiter EH, Gill RG (1994) Prevention of autoimmune diabetes in the BB rat by intrathymic islet transplantation at birth. J Endocrinol Invest 17: 595-599

7. Kaufman DL, Clare-Salzler M, Tian J et al. (1993) Spontaneous loss of T-cell tolerance to glutamic acid decarboxylase in murine insulin-dependent diabetes. Nature 366: 69-72

8. Tisch R, Yang X-D, Singer SM et al. (1993) Immune response to glutamic acid decarboxylase correlates with insulitis in nonobese diabetic mice. Nature 366: 72-75

9. von Herrath MG, Oldstone MB (1995) Role of viruses in the loss of tolerance to self-antigens and in autoimmune diseases. Trends Microbiol 3: 424-430

10. Rabinovitch A (1993) Roles of cytokines in IDDM pathogenesis and islet $\beta$-cell destruction. Diabetes 43: 215-240

11. Davies JL, Kawaguchi Y, Bennett ST et al. (1994) A genomewide search for human type 1 diabetes susceptibility genes. Nature 371: 130-136

12. Ghosh S, Palmer SM, Rodrigues NR et al. (1993) Polygenic control of autoimmune diabetes in nonobese diabetic mice. Nature Genetics 4: 404-409

13. Kockum I, Wassmuth R, Holmberg E et al. (1993) HLA-DQ primarily confers protection and HLA-DR susceptibility in type 1 (insulin-dependent) diabetes studied in population-based affected families and controls. Am J Hum Gen 53: 150-167

14. Borg LA, Cagliero E, Sandler S et al. (1992) Interleukin-1 $\beta$ increases the activity of superoxide dismutase in rat pancreatic islets. Endocrinology 130: 2851-2857

15. Pociot F, Molvig J, Wogensen L et al. (1992) A TaqI polymorphism in the human interleukin-1 beta (IL-1 beta) gene correlates with IL-1 beta secretion in vitro. Eur J Clin Invest 22: 396-402

16. Jacob H, Pettersson A, Wilson D et al. (1992) Genetic dissection of autoimmune type 1 diabetes in the BB rat. Nature Genetics 2: 56-60

17. Hosszufalusi N, Chan E, Teruya M et al. (1993) Quantitative phenotypic and functional analyses of islet immune cells before and after diabetes onset in the BB rat. Diabetologia 36: 11461154

18. Mojcik CF, Greiner DL, Medlock ES et al. (1988) Characterization of RT6 bearing rat lymphocytes. I. Ontogeny of the RT6 + subset. Cell Immunol 114: 336-346

19. Whalen BJ, Griner DL, Mordes JP et al. (1994) Adoptive transfer of autoimmune diabetes mellitus to athymic rats:synergy of CD4 + and CD8 + T cells and prevention of RT6 + T cells. J Autoimmunity 7: 819-831

20. Georgiou HM, Lagarde A-C, Bellgrau D (1988) T cell dysfunction in the diabetes-prone $\mathrm{BB}$ rat. A role for thymic migrants that are not T cell precursors. J Exp Med 167: 132-148

21. Elder ME, Maclaren NK (1983) Identification of profound peripheral $\mathrm{T}$ lymphocyte immunodeficiencies in the spontaneously diabetic BB rat. J Immunol 130: 1723-1731

22. Plamondon C, Kottis V, Brideau C et al. (1990) Abnormal thymocyte maturation in spontaneously diabetic BB rats involves the deletion of $\mathrm{CD}^{-} 8^{+}$cells. J Immunol 144: 923-928
23. Groen H, van d-B-JM, Nieuwenhuis P et al. (1989) Peripheral $\mathrm{T}$ cells in diabetes prone (DP) BB rats are CD45R-negative. Thymus 14: 145-150

24. Groen H, Klatter FA, Brons NHC et al. (1996) Abnormal thymocyte subset distribution and differential reduction of $\mathrm{CD} 4+$ and CD8 + T cell subsets during peripheral maturation in diabetes-prone BioBreeding rats. J Immunol 156: 1269-1275

25. Bellgrau D, Redd JM, Sellins KS (1994) Peculiar T-cell signaling does not preclude positive selection in the diabetes prone BB rat. Diabetes 43: 47-52

26. Markholst H, Andreasen B, Eastman S et al. (1991) Diabetes segregates as a single locus in crosses between inbred BB rats prone or resistant to diabetes. J Exp Med 174: 297-300

27. Jacob HJ, Brown DM, Bunker RK et al. (1995) A genetic linkage map of the laboratory rat, Rattus norvegicus. Nature Genetics 9: 63-69

28. Czerkinsky C, Andersson G, Ekre HP et al. (1988) Reverse ELISPOT assay for clonal analysis of cytokine production. I. Enumeration of gamma-interferon-secreting cells. J Immunol Meth 110: 29-36

29. Mustafa MI, Diener P, Hojeberg B et al. (1991) T cell immunity and interferon-gamma secretion during experimental allergic encephalomyelitis in Lewis rats. J Neuroimmunol 31: 165-177

30. Dagerlind A, Friberg K, Bean AJ et al. (1992) Sensitive mRNA detection using unfixed tissue:combined radioactive and nonradioactive in situ hybridization histochemistry. Histochemistry 98: $39-49$

31. Hornum L, Jackerott M, Markholst H (1995) The rat T-cell lymphopenia resistance gene (Lyp) maps between D4Mit6 and Npy on RNO4. Mamm Genome 6: 371-372

32. Olsson T, Bakhiet M, Höjeberg B et al. (1993) CD8 is critically involved in lymphocyte activation by a T.brucei-released molecule. Cell 72: 1-13

33. Moore KW, O'Garra A, de W-M-R et al. (1993) Interleukin-10. Annu Rev Immunol 11: 165-190

34. O'Garra A, Murphy K (1994) Role of cytokines in determining T- lymphocyte function. Curr Op Immunol 6: 458-466

35. Young HA, Hardy KJ (1995) Role of interferon- $\gamma$ in immune cell regulation. J Leuk Biol 58: 373-381

36. Zipris D, Greiner DL, Malkani S et al. (1996) Cytokine gene expression in islets and thyroids of $\mathrm{BB}$ rats: IFN- $\gamma$ and IL12p40 mRNA increase with age in both diabetic and insulintreated nondiabetic BB rats. J Immunol 156: 1315-1321

37. Rabinovitch A, Suarez-Pinzon W, El-Sheikh A et al. (1996) Cytokine gene expression in pancreatic islet-infiltrating leukocytes of BB rats: expression of Th1 cytokines correlates with beta-cell destructive insulitis and IDDM. Diabetes 45: 749-754

38. Whalen BJ, Rossini A, Mordes JP et al. (1995) DR-BB rat thymus contains thymocyte populations predisposed to autoreactivity. Diabetes 44: 963-967

39. Greiner DL, Mordes JP, Handler ES et al. (1987) Depletion of RT6.1 + T lymphocytes induces diabetes in resistant BioBreeding/Worcester (BB/W) rats. J Ex Med 166: 461-475

40. Thomas VA, Woda BA, Handler ES et al. (1991) Exposure to viral pathogens alters the expression of diabetes in $\mathrm{BB} /$ Wor rats. Diabetes 40: 255-258

41. Doukas J, Mordes JP, Swymer C et al. (1994) Thymic epithelial defects and predisposition to autoimmune disease in $\mathrm{BB}$ rats. Am J Path 145: 1517-1525

42. Petersen JS, Mackay P, Plesner A et al. (1995) Tolerance induction to GAD65 or BSA does not affect the time at onset or frequency of diabetes in the BB rat. Diabetologia 38:A 377 (Abstract)

43. Sarvetnick N, Shizuru J, Liggitt D et al. (1990) Loss of pancreatic islet tolerance induced by $\beta$-cell expression of interferongamma. Nature 346: 844-847

44. Kendall MD (1991) Functional anatomy of the thymic microenvironment. J Anat 177: 1-29 